\title{
The Effects of Jazz and Classical Music on Recall
}

Department of Psychology, Harding University, Box 14273, 915 E. Market Ave., Searcy, Arkansas, 72149, USA

\begin{abstract}
It is believed that recall is influenced by the tempo and style of music. The main purpose of the research was to discover if jazz or classical music effects the ability to recall information. It was hypothesized that classical music at 60 and 120 beats per minute was more effective than jazz music at 60 and 120 beats per minute. In the present study, a two by two dimension will be used to compare jazz and classical music at 60 beats per minute and 120 beats per minute to observe how much material individuals can remember. 60 randomly selected individuals read a comprehensive GRE passage for 5 minutes. Although there were many limitations in this study, it serves to show the importance in developing methods for better recall.
\end{abstract}

\section{Keywords: Recall; Music; Classical; Jazz; Tempo; Style}

\section{Introduction}

Jazz and classical music have influenced humans for decades. According to Deveaux, "more than a third (34\%) of the adult population said they "liked" jazz..." [1]. Classical and jazz composers such as Ludwig Van Beethoven, Johann Sebastian Bach, Louis Armstrong, and Miles Davis have created musical pieces that are not only pleasurable to hear but can be used to aid with studying and recall. It is important to understand the role music plays in knowing how to improve attributes such as test taking skills, memorization, and concentration. According to How Music Affects us and Promotes Health classical music with slower beats per minute has been shown to aid with the recall of material and also assists with the reduction of stress. This study will take an in-depth look into how jazz and classical music, created at different tempos, affects recall.

\section{Literature Review}

Music's effect on recall continues to spark the interest of many researchers. Rickard et al. conducted a study on the benefits of instrumental music on memory [2]. The use of instrumental rather than lyrical music adds a different perspective to this study. These researchers were interested in young children who are musically inclined. Following the proposal of the study, children were observed a year later and showed greater improvements of verbal memory. The primary focus was on what type of musical training aids verbal memory. In other words, the ability to play an instrument was related to recall. Most research regarding music and memory focuses on the tempo of lyrical music and its connection to cognitive functioning of the brain; however, Rickard et al. proposed that verbal learning is enhanced through the use of stringed instruments [2]. Although the piano is not a stringed instrument, individuals who learned to play had an increased self-esteem as well as a noticeable improvement in literacy skills that contributed to recall but did not prove that it is the cause of verbal memory [2]. The conclusion of this research study was disputed by other researchers. Jancke et al. stated that "there was no influence of background music for verbal learning" [3]. A similar idea was proposed in the journal How Music Affects Us and Promotes Health arguing that music does in fact affect recall. The role of music on recall has produced inconsistent results. Therefore, further research is needed to establish the correlation between types of music and recall.

Researchers Quintin et al. characterized this study by suggesting three ways that music helped with Autism Spectrum Disorder [4]. First, communication of emotions between a caregiver and the diagnosed individual is a main component that contributes to the effect of music. Altenmuller et al. [5] highlighted the main purpose through the use of the quote "music is communicated, mostly, but not exclusively, through sound, which is relatively slow mechanical energy...". For instance, a person may not be able to hear which means that learning through the use of sign language would be one of few options. Second, employing music reduces reliance on verbal material. The importance of verbal material should be a primary focus [2]. Individuals use nonverbal communication to display a message that would otherwise have no significance. For instance, gestures during a song instead of lyrics may communicate more than one message which decreases the reliance on verbal material. The use of nonverbal language aids individuals by increasing recall [4]. Lastly, the amygdala is stimulated during social emotions and while listening to music for individuals. For example, a person who experiences sorrow during interpersonal relationships would show signs of processing complex information.

Moreover, it has been found that classical music at 60 beats per minute may reduce anxiety and could also improve memory [6]. This shows that music playing at a slower rate could cause individuals to be more calm and at ease. According to How Music Affects Us and Promotes Health, Mozart's music has the ability to activate both sides of the brain that makes it capable of processing information. This suggests that music assists with the ability to recall information after it is processed. A common trend that was evident in this study was the research on the enhanced functioning of minds of people who already played an instrument. In an attempt to prove the claim, Goldenberg et al. directed a study that tested the effects of music on test anxiety [7]. The use of the quote, "if arousal rather than a specific effect of Mozart's music was operating, then any music that participants enjoyed would be related to better performance" shows that if any form of music was liked by participants, then anxiety would reduce and it would resort to better grades [7]. These findings do not show a clear differentiation between musical speed or tempo and its effect on emotions including anxiety.

*Corresponding author: Kelsey Pope, Department of Psychology, Harding University, Box 14273, 915 E. Market Ave., Searcy, Arkansas, 72149, USA, Tel: 8704945893; E-mail: kpope1@harding.edu

Received April 05, 2017; Accepted May 10, 2017; Published May 12, 2017

Citation: Pope K (2017) The Effects of Jazz and Classical Music on Recall. J Health Educ Res Dev 5: 215. doi: 10.4172/2380-5439.1000215

Copyright: () 2017 Pope K. This is an open-access article distributed under the terms of the Creative Commons Attribution License, which permits unrestricted use, distribution, and reproduction in any medium, provided the original author and source are credited. 
In addition to the research mentioned earlier, O’Donnell added, "Mozart's music and baroque music, with 60 beats per minute beat pattern, activate the left and right brain" [8]. This study shows that music does not influence one side of the brain. For example, an individual may be able to recall more information in a passage after listening to slower classical music. The ability to use both sides of the brain shows the complexity of the human brain through the use of music. It is also believed that the tempo of music is one of the key components for memory (1999). To expand on O'Donnell's research, Adrian Cho adds, "tempo is the overall pace of an activity" [8,9]. This statement sums up the meaning of tempo. For instance, tempo can be compared to a drum because each one contributes to the speed of activities. Tempo is needed to maintain the motion of the music. In this study, a jazz composer known as Duke Ellington played at 280 beats per minute (2010) which gives the music a different feel. Even though listening to background music in this tempo is not common, O'Donnell concluded this form of music does enter the memory alongside learned information.

Furthermore, Oakes et al. used two experiments to show how background music that displays a different timbre and tempo contributes to ad content recall and response [10]. The study gave a common description of what tempo is declaring "musical tempo is the speed at which a musical passage progresses". Individuals, according to Fraser et al. can expect recall to be a negative function of music tempo [11]. Although the two studies display different views of tempo and its effect on the brain, they both give a clear method that aids researchers in understanding what musical tempo and timbre is. The purpose of the studies was to test the claim that music does have an impact on ad recall. ad recall means that individuals remember what has been heard or seen on a commercial or advertisement. Although research in this area was difficult to conduct, both studies used two experiments that are helpful in understanding the above concepts.

The studies above looked at the use of experiments based on music. The purpose of these studies was to explain music's effect on recall, verbal memory, disorders, and anxiety. Some of the studies even exemplify the effect of slow classical music which will be tested in a future study that addresses beats per minute. The Mayo Health Clinic conducted a study that coined the term "mind aerobics" [12]. This means that music stimulates the mind in an active way that could be compared to physical fitness. Likewise, O'Donnell believes the power of music cannot be rejected. Overall, these studies give future researchers a new profound knowledge of what needs to be further studied [8].

\section{Purpose and Rationale}

Previous research has suggested that background music is not a part of learning $[6,8]$, but the tempo of music could aid in recall and improve scores if listened to before test taking. Since it has been shown that classical music improves memorization, then would jazz music do the same thing? The null hypothesis is there is no difference between which form of music is most effective for memorization of the assigned texts. If slower music increases what people can recall, then can faster music decrease what can be recalled? This study will attempt to answer these questions. The purpose of the present study is to incorporate all of the ideas from previous research to prove which style and tempo of music is best for recall. This information could be used to aid other researchers in finding out methods that will increase test scores. It could also serve as information about how to treat individuals who have disorders such as Specific Learning Disorder or Intellectual Disability Disorder. Overall, this research will aid in eliminating obstacles that may have been presented before.

\section{Methods}

\section{Participants}

60 participants were selected to complete this study. Each randomly selected participant was required to be 18 years of age or older. 31 of the participants were female and 29 of the participants were male. Of the participants, the ethnicities included Caucasians, African Americans, and Asians.

\section{Materials}

In this research study, the materials encompassed consent forms, a GRE passage, and questions. On the first page of the survey, participants were asked to state their name and the date. In order to keep track of who was surveyed, gender was documented after the study was completed. The GRE passage was tested by a Coh-Metrix analysis and proved to be on a $10^{\text {th }}$ grade reading level. Five questions were created by the researcher pertaining to the passage.

\section{Design}

By using SPSS, data was examined using the one-way between subjects' analysis of variance (ANOVA) and a t-test. The post-test scores were the dependent variables and the condition as well as gender were the independent variables.

\section{Procedure}

In person, 60 surveys were dispersed throughout various places in Arkansas. All 60 surveys were submitted: however, 7 were done incorrectly and had to be redone by different individuals. Each set of questions was scored by hand and put into SPSS on a scale of one to five; the number being how many questions participants got correct.

\section{Results}

Using the one-way ANOVA and t-test, there was no significant effect on the style and tempo of music and how it effects recall. With the condition, $\mathrm{F}(3.56)=0.824, \mathrm{p}>0.05$. Furthermore, there was no significant correlation between gender and post-test scores, $\mathrm{t}(58)=0.928, \mathrm{p}>0.05$. According to this, there is little difference between which type of music can be used during studying. For those who prefer jazz, there is little difference in what is remembered as opposed to individuals who prefer classical music. The chart below shows the overall percentage of correct answers within one of the styles of music (Figure 1).

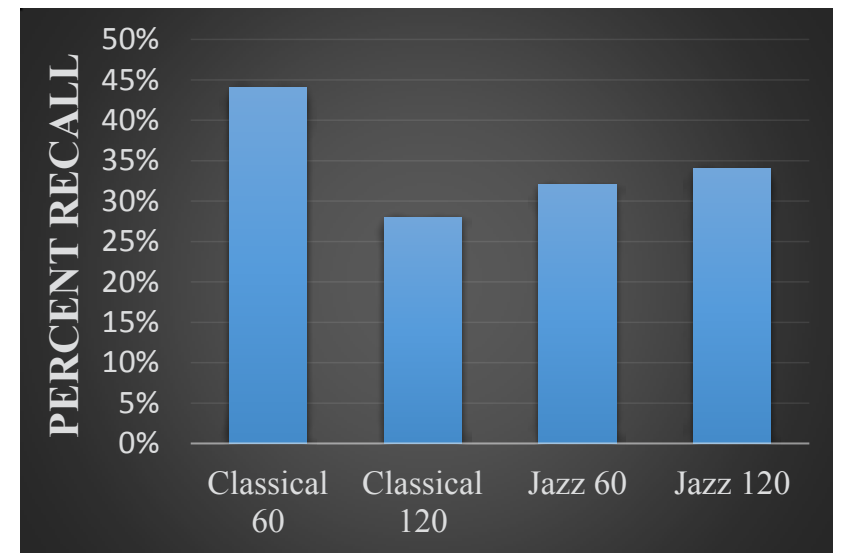

Figure 1: The overall percentage of correct answers within one of the styles of music. 


\section{Discussion}

Previous research suggests that there is a significant difference between classical and jazz music and its effects on recall. Therefore, the condition in which each participant was put in did not influence the overall score. Because there were so many inconsistent factors that must be taken into consideration. In the beginning of the study, the present researcher faced limitations with randomizing participants, individuals who did not answer any questions, and other distractions in the environment while listening to one of the four forms of music. This may have influenced the way questions were answered causing some to be able to answer fewer questions correctly. The study also consisted of open-ended questions which was a bit harder to grade as opposed to multiple choice. Had there been more preparation and a quieter environment, more significant correlations would be present.

For further research, future studies may include a group that listens to no music at all. No control group proved to be another limitation in this study. In addition, more participants may be added to the study. The major surprises were males $(M=1.90)$ tended to answer more correct questions than females $(\mathrm{M}=1.55)$ and participants selected for classical at $60 \mathrm{bpm}$ answered the most correct questions, but the results showed no significance in this finding. Future researchers should be mindful of this finding.

\section{References}

1. DeVeaux SK (1999) Jazz in America: Who's Listening? Jazz Journalists Association Library. EMedExpert - Reliable Information on Prescription Drugs. Surprising Effects of Music.
2. Rickard NS, Vasquez JT, Murphy F, Gill A, Toukhsati SR (2010) Benefits of a Classroom Based Instrumental Music Program on Verbal Memory of Primary School Children: A Longitudinal Study. Australian Journal of Music Education 1: $36-47$.

3. Jäncke L, Sandmann $P$ (2010) Music listening while you learn: no influence of background music on verbal learning. Behavioral and Brain Functions 6: 3.

4. Quintin E, Bhatara A, Poissant H, Fombonne E, Levitin DJ (2011) Emotion Perception in Music in High-Functioning Adolescents with Autism Spectrum Disorders. Journal of Autism and Developmental Disorders 41: 1240-1255.

5. Altenmüller E, Demorest S, Fujioka T, Halpern A, Hannon E, et al. (2012) Introduction to the Neurosciences and Music IV: Learning and Memory. Annals of the New York Academy of Sciences 1252: 1-16.

6. Cash AH (2009) The Brain and Music. The Brain and Music: Improving Test Scores with Music.

7. Goldenberg MA, Floyd AL, Moyer A (2013) No Effect of a Brief Music Intervention on Test Anxiety and Exam Scores in College Undergraduates. Journal of Articles in Support of the Null Hypothesis 10: 1-16.

8. O'Donnell L (1999) Revista. Music and the Brain.

9. Cho A (2010) InformIT: The Trusted Technology Source for IT Pros and Developers. Tempo the Jazz Process: Maintain Momentum InformIT.

10. Oakes S, North AC (2006) The Impact of Background Musical Tempo and Timbre Congruity upon Ad Content Recall and Affective Response. Applied Cognitive Psychology 20: 505-520.

11. Fraser C, Bradford JA (2013) Music to your brain: Background music changes are processed first, reducing ad message recall. Psychology \& Marketing 30: $62-75$.

12. (2007) Maintaining your Brain. Mayo Clinic Health Letter 25: 4-5. 